https://doi.org/10.7203/Normas.2.4661

\title{
EL TRATAMIENTO ORTOGRÁFICO, ORTOTIPOGRÁFICO Y LEXICOGRÁFICO DE LOS EXTRANJERISMOS CRUDOS EN LA PRENSA ESCRITA ESPAÑOLA
}

\author{
THE ORTHOGRAPHIC, ORTHOTYPOGRAPHIC AND LEXICOGRAPHIC TREATMENT \\ OF FOREIGN WORDS IN THE SPANISH WRITTEN PRESS
}

DUNIA HOURANI MARTÍN

Universidad de Granada

\section{RESUMEN:}

En 2010, la Real Academia Española publicó una nueva obra ortográfica en la que introdujo una serie de novedades y cambios normativos que rompían en muchos aspectos con la obra anterior de 1999. Esta serie de cambios llevados a cabo también afectaron al ámbito de los extranjerismos crudos. En este trabajo nos ocupamos de la repercusión que tienen las normas ortográficas y lexicográficas de la Academia en la prensa escrita española, centrando nuestra atención en la representación gráfica de los extranjerismos crudos. Para el estudio, rastreamos las voces foráneas en un corpus compuesto por periódicos y revistas de divulgación y analizamos cuantitativa y cualitativamente los datos obtenidos. Nuestro análisis demuestra que los medios de comunicación mantienen un alto grado de corrección normativa.

PALABRAS CLAVE: extranjerismo crudo, ortografía, ortotipografía, lexicografía, norma lingüística.

\section{ABSTRACT:}

In 2010 the Royal Spanish Academy published a new orthograpic book in which they introduced novelties and normative changes that broke in many aspects with the previous guidelines in 1999. Those changes also affected the field of foreign words. This article discusses the effects of the Academy's orthographic and lexicographic norms in the Spanish written press, and we focus our attention on the typographic representation of foreign words. This paper will search for foreign words in a corpus of newspapers and general interest magazines and analyze quantitatively and qualitatively the information obtained. Our analysis leads to the conclusion that the media keep a high degree of normative correctness.

KEY WORDS: foreign word, orthography, orthotypography, lexicography, linguistic norm.

NORMAS. REVISTA DE ESTUdIOS LINGÜÍSTICOS HISPÁNICOS, NÚMERO 2 (AÑO 2012):

http://www.uv.es/normas

(ISSN 2174-7245) 


\section{INTRODUCCIÓN}

El léxico de las lenguas se amplía y evoluciona gracias a la incorporación de palabras o expresiones que pertenecen a otros idiomas y que designan realidades nuevas para las que esa lengua no dispone de un término concreto. El español se ha visto enriquecido a lo largo de la historia por préstamos lingüísticos procedentes de otros idiomas, de esto no cabe duda. Sin embargo, muchas veces la inclusión de dichas palabras no solo se produce por necesidad, sino por lo que la Academia define como «mimetismo lingüístico hacia lenguas de gran prestigio» ${ }^{1}$ (ORAE, 2010: 596). Este último caso puede llegar a relegar a un segundo plano términos existentes en nuestra propia lengua o, en el peor de los casos, desestabilizar la unidad ortográfica del español.

Bien es cierto que normalmente los extranjerismos crudos ${ }^{2}$ acaban adaptándose a las convenciones ortográficas españolas. No obstante, esta evolución constituye un proceso lento y laborioso; la Academia vigila el uso de estas voces por parte de los hablantes antes de tomar una decisión y procura dirigir el proceso para que su incorporación a nuestro sistema se lleve a cabo de acuerdo con las normas establecidas en nuestra lengua. Sin embargo, en ocasiones su pronunciación al respecto llega tarde y no se corresponde con la realidad lingüística del momento, por ejemplo, debido a que los hablantes ya se han familiarizado con las grafías extranjeras ${ }^{3}$. Asimismo, también podemos encontrar términos que presentan mayor resistencia a la adaptación dado que se usan en el panorama internacional con su grafía original, como ballet ${ }^{4}$ o rock; porque sus propuestas españolas no han tenido éxito, como es el caso de mercadotecnia para la voz inglesa marketing; o por designar realidades que solo existen en el ámbito de la lengua de origen, sharia o sheriff.

En todo este proceso, el papel divulgativo de los medios de comunicación, en general, y de la prensa escrita, en particular, es esencial. El lenguaje periodístico, además de abarcar numerosos ámbitos de conocimiento (política, economía, deporte, etc.), es creativo, produce neología, acuña extranjerismos y marca tendencias en los hábitos lingüísticos de los hablantes. Por esto, hemos querido centrar nuestra

\footnotetext{
${ }^{1}$ Martínez de Sousa (2004: 46) explica este mimetismo ortográfico como «la copia, normalmente inconsciente, de grafismos no idiomáticos en español, correspondientes a sistemas ortográficos de otros idiomas (extranjerismos ortográficos)».

${ }^{2}$ Nos hemos decantado por la opción terminológica extranjerismo crudo pues es la aplicada por la Academia, tanto en la $O R A E$ como en el $D P D$, para denominar las voces ajenas a nuestro sistema fonológico y ortográfico; y que se contrapone a las voces «que han experimentado ciertas variaciones formales con el fin de adecuarse al sistema fonológico, ortográfico y morfológico propio de nuestra lengua» (ORAE, 2010: 602) o extranjerismos adaptados. Otros términos para designar las voces extranjeras son préstamos, en general, cuya polisemia puede conducir a error, préstamos integrales (Gómez Capuz 2004: 52) y palabras extranjeras o xenismos (Guerrero Ramos, 1995: 37).

${ }^{3}$ Este sería el caso de voces como whisky y hippie, cuyas grafías originales difieren mucho del sistema ortográfico español, pero, sin embargo, nos resultan menos chocantes que sus adaptaciones españolas güisqui y jipi, respectivamente.

${ }^{4}$ Todos los ejemplos citados en el presente trabajo se han extraído de nuestro corpus.
} 
investigación en la prensa escrita y observar el empleo de los préstamos lingüísticos, en concreto, de los extranjerismos crudos.

Pero ¿hasta cuándo un término es un extranjerismo crudo y cuándo pasa a convertirse en un préstamo lingüístico adaptado? Para poder hacer esta distinción, tenemos que empezar definiendo los extranjerismos crudos o no adaptados, que «son aquellos que se utilizan con la grafía y la pronunciación (más o menos exacta o aproximada) que tienen en su lengua de origen, y no se ajustan, por ello, al sistema fonológico ni ortográfico del español» (ORAE, 2010: 597). Por lo tanto, han de estar marcados gráficamente para que se puedan reconocer como ajenos en un texto escrito en castellano.

\section{HIPÓTESIS Y METODOLOGÍA}

El 17 de diciembre de 2010, la Real Academia Española publicó una nueva obra ortográfica en la que introdujo una serie de novedades y cambios normativos, rompiendo en muchos aspectos con la obra anterior de 1999. Esta serie de cambios llevados a cabo también afectaron al ámbito de los extranjerismos crudos, objeto de nuestro trabajo. Dado que ha trascurrido ya alrededor de un año y medio desde su publicación, nuestro propósito es analizar la repercusión de las normas ortográficas y, por ende, el grado de cumplimiento de la mismas en la prensa escrita actual, así como también estudiar los procedimientos de marcado empleados para señalar el carácter foráneo de las voces extranjeras, abordando dicho análisis desde el parámetro ortográfico, el ortotipográfico y el lexicográfico. Desde los puntos de vista ortográfico y ortotipográfico consideraremos extranjerismo crudo toda unidad léxica foránea que aparezca en nuestro corpus con su grafía y pronunciación etimológicas y observaremos el procedimiento seguido para su marcado gráfico; y desde el punto de vista lexicográfico, tendremos en cuenta que dicha voz extranjera no esté desplazando un término patrimonial español. Nuestra hipótesis de partida consiste, pues, en que la prensa escrita y, en concreto, los periodistas, por su responsabilidad como profesionales que trabajan con la lengua y, en muchas ocasiones, porque son modelos a seguir, cumplirán las normas académicas para el tratamiento ortográfico, el ortotipográfico y el lexicográfico de los extranjerismos crudos.

El primer paso en nuestra investigación fue elegir el corpus en el que se buscarían los extranjerismos crudos. Decidimos seleccionar tanto periódicos como revistas; de manera que pudiésemos cubrir diferentes modelos de prensa escrita, en cuanto al formato y a la información contenida. Así, al ser un periódico una publicación diaria que se centra fundamentalmente en acontecimientos actuales y noticiosos, exige inmediatez, y, por lo tanto, el tiempo para el control y la corrección de los contenidos es menor que en otro tipo de publicaciones; como contraposición, hemos seleccionado 
revistas mensuales, dedicadas a reportajes, revisión de sucesos y noticias relativamente actuales.

Los periódicos elegidos, correspondientes al domingo 22 de enero de 2012, son $E l$ País, Público, ABC, El Mundo e Ideal. Por un lado tenemos cuatro de los periódicos de tirada nacional más leídos en España y que representan las distintas ideologías (centroizquierda: El País; izquierda: Público; derecha: $A B C$; centro-derecha: El Mundo), y, por otro, uno de tirada regional, el periódico Ideal, que es uno de los más leídos en la Andalucía oriental y que pertenece al grupo Vocento. Todas las publicaciones anteriormente citadas, salvo el diario Público, tienen una edición de domingo, más extensa y que viene acompañada de suplementos dominicales y revistas, motivo por el cual se han seleccionado los periódicos tal día.

Nuestro corpus se completó con cuatro revistas de divulgación ${ }^{5}$ de periodicidad mensual, correspondientes al mes de enero de 2012, que abarcan diferentes temas y que están dirigidas a un público general. Estas publicaciones son Muy Interesante, que trata temas como la ciencia, la tecnología, la historia, el medio ambiente y el futuro; Le Monde Diplomatique, con reportajes sobre actualidad, política internacional y cultura; Actualidad económica, que, como su nombre indica, es publicación sobre economía; y Geo, que aborda temas como tecnología, ciencia, historia, cultura, sociedad y actualidad.

Una vez seleccionadas las fuentes primarias, hemos rastreado los extranjerismos crudos que han ido apareciendo: tanto palabras, locuciones, citas o dichos en lengua extranjera como las formas híbridas, que ni están completamente adaptadas al español ni tienen forma extranjera. Sin embargo, en nuestra búsqueda no han tenido cabida los extranjerismos adaptados, ya que están adecuados a las reglas ortográficas del español ${ }^{6}$; así como tampoco los nombres propios, por constituir estos un campo de estudio en sí mismos y acogerse a unas normas ortográficas distintas (cfr. ORAE, 2010: cap. VII. «La ortografía de los nombres propios»).

\footnotetext{
${ }^{5}$ No era nuestra intención analizar publicaciones especializadas por tres cuestiones. Primero, por el tipo de textos y la especificidad de los temas tratados. La prensa divulgativa hace uso de extranjerismos ya afianzados como términos concretos y pertenecientes a la lengua general; aunque, es cierto que algunas veces también recurre a extranjerismos con cierto grado de especialidad correspondientes a un ámbito concreto como la economía. Sin embargo, la prensa especializada es más propensa y, en ocasiones, se ve forzada a adoptar nuevos términos (sobre todo procedentes del mundo anglosajón) que responden a las realidades más actuales en los ámbitos de especialidad para los que nuestra lengua no dispone de solución inmediata, como ocurre en el campo de las nuevas tecnologías. Segundo, nos interesa el lector al que la publicación se dirige, nosotros queremos analizar publicaciones de carácter divulgativo orientadas a un público general. Es el hablante de a pie el que extenderá el uso de las palabras extranjeras y el que será tenido en cuenta para la incorporación de dichos términos en el diccionario académico. Tercero, el autor del artículo debe reflejar el uso real de la lengua. El periodista, si bien muchas veces está especializado en un ámbito concreto, está más cerca de la lengua general que de la especializada, por lo tanto, su discurso es divulgativo y no está tan influido como el del experto por voces extranjeras o terminología propia.

${ }^{6}$ Muy útil ha resultado en este sentido la edición en línea del $D R A E$, que presenta los avances de la 23. ${ }^{\text {a }}$ edición del diccionario. Así, términos como bonus, hándicap o suflé que aparecían en nuestro corpus, ya están admitidos y no se consideran ajenos a nuestra lengua.
}

NORMAS. REVISTA DE ESTUDIOS LINGÜÍITICOS HISPÁNICOS, NÚMERO 2 (AÑO 2012):

http://www.uv.es/normas

(ISSN 2174-7245) 
Todas las voces foráneas encontradas se han recogido en una base de datos para cuya confección se consideraron diferentes variables. Por un lado, hemos contemplado dos variables dependientes en las que se basará nuestro análisis: la variable 1 (norma académica ortográfica y ortotipográfica) y la variable 1' (norma académica lexicográfica); y, por otro, el resto de variables, en función de las cuales observaremos el comportamiento de las variables dependientes y extraeremos las conclusiones oportunas. A continuación, exponemos las variables que han resultado ser más representativas para la realización del presente estudio y sus respectivas variantes:

Variable 1: Norma académica ortográfica y ortotipográfica

0 . Sigue la norma académica ortográfica y ortotipográfica

1. No sigue la norma ortográfica

2. No sigue la norma ortotipográfica

3. Se trata de una forma híbrida

Esta variable indica si se cumplen o no la directrices académicas. Hemos incluido todas las variantes que pudieran tener relevancia: la variante 0 correspondería a la situación ideal en la que el extranjerismo está marcado con cursiva o comillas (ejemplos: ranking o «ranking»). En la variante 1 la voz extranjera no se encuentra marcada ni con cursiva ni con comillas (ejemplo: ranking). En la variante número 2 la palabra o expresión se encuentra hipercaracterizada (ejemplo: «ranking»). La última variante comprende aquellos casos en los que la palabra ha dejado de tener forma foránea, pero tampoco se encuentra adaptada (ejemplo: ránking, que ni se ajusta a la forma inglesa ranking, ni a la española ranquin, o foto finish, que es mitad español, mitad inglés). Asimismo, los latinismos que hayan sido tratados como voces españolas y, por ende, acentuados gráficamente de acuerdo con la ORAE de 1999 (vid. § 2), también han sido incluidos dentro de la variante 3, por no seguir la normativa ortográfica vigente, es decir, la $O R A E$ de 2010 , en la que se ha equiparado el tratamiento ortográfico de dichas voces al del resto de lenguas extranjeras.

Variable 1': Norma académica lexicográfica

0 . Existe un término alternativo o equivalente

1. No existe ningún término alternativo ni equivalente

En nuestro trabajo también pretendemos analizar cualitativamente los datos del corpus, por ello hemos tenido en cuenta la variable lexicográfica. Nos basaremos en el $D P D$, como norma vigente para establecer el parámetro lexicográfico. En la variante 0 abarcamos tanto los casos en los que existe un término español alternativo o equivalente 
para la voz extranjera, como aquellos para los que existe una propuesta por parte de la Academia $^{7}$, por ejemplo: coach o impasse, cuyo uso es innecesario por existir en español términos como entrenador o preparador y callejón sin salida o punto muerto, respectivamente; y derby o magazine, para los que, aunque el DPD por su extensión en español admita el empleo de los mismos o de las formas adaptadas derbi y magacín, señala que no hay que olvidarse de que existen las equivalencias españolas clásico y revista o programa de variedades, respectivamente. No se trata de buscar las adaptaciones fónicas y gráficas de los extranjerismos - que hemos incluido dentro de la variante $1-$, sino de observar si existe un término patrimonial que esté siendo desbancado por la voz foránea; en cuyo caso, se estaría desatendiendo y, por lo tanto, incumpliendo la norma lexicográfica académica. La variante 1, sin embargo, comprende todos aquellos extranjerismos para los que no existe un término alternativo o equivalente en español y se han incorporado a nuestro idioma con la grafía y pronunciación original, como blues, bossa-nova y suite; para los que encuentran adaptación fónica y gráfica en español, pero no un término patrimonial alternativo, como sería el caso de clic, máster o rosbif para los anglicismos click, master y roast beef, respectivamente; así como para los que hubieran podido traducirse fácilmente en su contexto, pero, por la razón que fuere, se han preferido mantener como voces extranjeras, por ejemplo: las voces en lenguas vernáculas estadi ('estadio') o gaiteiro ('gaitero'); o en otras lenguas extranjeras como atelier ('taller'), femme fatale ('mujer fatal') o reality show ('programa de telerrealidad') 8 .

${ }^{7}$ En el $D P D$ «se diferencian los extranjerismos superfluos (los que se usan sin necesidad por existir voces o expresiones españolas de igual sentido) de los extranjerismos que se consideran necesarios o ya plenamente arraigados en el uso. Para estos últimos, se hacen propuestas de adaptación o se sugiere el empleo de equivalencias en español, sin dejar de reconocer aquellos que se han asentado en el uso internacional con su grafía y pronunciación originarias» $(O R A E, 2010: 599)$. En la página web del $D P D$ (http://buscon.rae.es/dpdI/) podemos encontrar un ejemplo de extranjerismo superfluo en: «copyright. Voz inglesa que significa 'derecho de explotación y reproducción de una obra intelectual, artística o científica'. En español debe sustituirse por la equivalencia derecho(s) de autor o derecho(s) de edición. [...] Como convención internacional se usa la palabra inglesa, o su símbolo @ , en la contraportada de los libros, precediendo al nombre del titular de los derechos». Y como ejemplo de extranjerismo necesario o plenamente arraigado tenemos: «byte. Voz inglesa (pron. [báit]) que designa, en informática, el carácter o unidad de información compuesto de ocho bits. [...] Su plural es bytes (pron. [báits]). Por tratarse de una unidad de medida de circulación internacional, se emplea normalmente como extranjerismo crudo, con su grafía y pronunciación originarias, aunque no debe olvidarse que el equivalente español de este anglicismo es octeto» (DPD: http://buscon.rae.es/dpdI/).

8 En este sentido la Fundación del Español Urgente a través de su página web: http://www.fundeu.es/ realiza una gran labor de normalización de términos extranjeros, solventando dudas y proponiendo alternativas y traducciones para términos foráneos, que muchas veces considera innecesarios: es el caso de spread y conference call —entre los muchos ejemplos hallados en nuestro corpus-, cuyo uso recomienda evitar y propone optar por los términos españoles diferencial y multiconferencia, respectivamente. También los distintos libros de estilo consultados incorporan un apéndice léxico en el que recogen términos problemáticos, entre los que se encuentran los extranjerismos crudos, cuyo empleo regulan y para los que, en la mayoría de los casos, proporcionan una alternativa española.

NORMAS. REVISTA DE ESTUDIOS LINGÜÍSTICOS HISPÁNICOS, NÚMERO 2 (AÑO 2012):

http://www.uv.es/normas

(ISSN 2174-7245) 
Variable 2: Publicación

0. El País

1. Público

2. $A B C$

3. El Mundo

4. Ideal

5. Muy Interesante

6. Geo

7. Le Monde Diplomatique

8. Actualidad Económica

Al estar nuestro corpus compuesto tanto por periódicos como por revistas, hemos creído conveniente distinguir las publicaciones en las que aparece el extranjerismo, para observar cuáles son más propensas a la inclusión de palabras extranjeras en los textos españoles, así como para ver si cumplen la norma ortográfica de la Academia para el marcado de dichas voces.

Variable 3: Origen del extranjerismo

0 . Voz latina

1. Voz inglesa

2. Voz francesa

3. Voz alemana

4. Voz catalana

5. Voz vascuence

6. Voz gallega

7. Voz italiana

8. Voz rumana

9. Voz árabe

10. Voz griega

11. Voz japonesa

12. Voz portuguesa

13. Voz sesotho 
14. Voz china

15. Voz javanesa

16. Voz polaca

17. Voz tailandesa

18. Lengua de Matupit

19. Voz neerlandesa

La variable del origen del extranjerismo nos parece fundamental en nuestro análisis para observar qué lengua extranjera tiene más presencia en los textos escritos en español. Como variantes hemos incorporado todas aquellas lenguas que son fuente de préstamos léxicos para el español, como son el latín, fundamental en la creación de neología técnica y científica y en el empleo culto tanto de expresiones univerbales como pluriverbales; el inglés, del que proceden voces que responden a realidades nuevas en campos en constante evolución como la tecnología, la economía o la cultura; el francés, lengua de la cual hemos incorporado muchas voces, sin embargo no todas se encuentran acomodadas a los patrones ortográficos españoles; el alemán; las tres lenguas vernáculas cooficiales con el español, que adquieren mucha importancia en las noticias nacionales. Las demás lenguas incluidas entre las variantes han surgido del muestreo exploratorio del corpus.

Variable 4: Tipo de extranjerismo

0 . Sustantivo

1. Locución

2. Adjetivo

3. Adverbio

4. Verbo

5. Pronombre

6. Preposición

Hemos considerado que determinar la categoría morfológica de la voz extranjera podría tener relevancia a la hora de extraer conclusiones. Nos proponemos observar qué tipos de palabras extranjeras incorporamos preferentemente a nuestro discurso.

Asimismo, queremos destacar que dentro de la variante «sustantivo» hemos recogido tanto sustantivos comunes, como tecnicismos latinos o latinizados; y dentro de la variante «locución» se registran también los casos de los nombres compuestos. 
Variable 5: Procedimiento para marcado

0 . No marcado

1. Cursiva

2. Redonda con comillas españolas

3. Redonda con comillas inglesas

4. Redonda con comillas simples

5. Redonda con distintas comillas

6. Cursiva con comillas simples

7. Cursiva con comillas españolas

8. Cursiva con comillas inglesas

9. Redonda en negrita

10. Solo una comilla

11. Redonda, cuando el texto está en cursiva

Esta variable se centra en el procedimiento de marcado de los extranjerismos, si es que lo hubiese. La variante 0 corresponde a los casos en los que no están marcados. La variante 1 distingue las voces extranjeras marcadas con cursiva, que es lo indicado por la Academia preferentemente en la escritura tipográfica (vid. § 2), y las variantes 2,3 y 4 comprenden los casos en los que dichas voces están marcadas con comillas (españolas, inglesas y simples, respectivamente), lo que no supone una incorrección, pero sí un desvío de la norma académica que prefiere reservar las comillas para otros casos (vid. ORAE, 2010: 380-386). La variante 5 hace referencia a los casos en los que coinciden comillas simples e inglesas y se suprime la comilla de cierre simple. Las variantes 6,7 y 8 corresponden a los supuestos de hipercaracterización, en los que no se cumplen las normas ortotipográficas. Las demás variantes han surgido del muestreo exploratorio.

Variable 6: Lugar del texto en el que aparece

0 . Titular, subtítulo o ladillo

1. Cuerpo del texto

Dado que los titulares tienen un tratamiento ortotipográfico distinto al resto del cuerpo del texto (vid. $\S 2$ ), hemos tenido en cuenta esta variable. Los pies de foto se han incluido dentro de la variable 1. 
Para el análisis cuantitativo de los datos recogidos hemos trabajado con el paquete estadístico SPSS ${ }^{\circledR}$.

\section{ESTADO DE LA CUESTIÓN}

Nuestra investigación se fundamenta en un corpus base constituido tanto por las obras ortográficas académicas, como por libros de estilo para periodistas y un manual de ortografía y ortotipografía. A continuación vamos a exponer brevemente la norma académica y las soluciones aportadas por las demás obras consultadas para destacar las voces foráneas en un texto escrito en español.

La obra ortográfica de 1999 dispone que las voces extranjeras no adaptadas han de distinguirse en la escritura «mediante el uso de procedimientos gráficos como las comillas, la letra cursiva, etc. Ejemplos: affaire, lady, whisky» (ORAE, 1999: 29-30). Así, al proponer alternativas, en principio, intercambiables, obliga al usuario a remitirse al apartado sobre los usos de las comillas (ORAE, 2010: vid. cap. V. «Puntuación», $\S 5.10$.) para descubrir que en los textos impresos es más frecuente utilizar la cursiva como marcado de extranjerismos.

La nueva ORAE de 2010 solventa el problema concretando el tratamiento ortográfico de las voces extranjeras, así como también de las locuciones, dichos o citas en otro idioma y dicta que:

\footnotetext{
Deben escribirse siempre en los textos españoles con una marca gráfica que destaque su condición de palabras pertenecientes a otra lengua: preferentemente en cursiva en la escritura tipográfica (siempre que el texto base esté escrito en redonda; pero en redonda si el texto base está escrito en cursiva) y entre comillas en los textos manuscritos, donde no es posible establecer la oposición entre la letra redonda y la cursiva (ORAE, 2010: 601).
}

Es cierto que la $O R A E$ reconoce estos dos procedimientos de marcado; sin embargo, en el apartado referido a los usos de las comillas (vid. ORAE, 2010: cap. III. «El uso de los signos ortográficos», § 3.4.8.2.1.) señala que «en textos impresos en letra redonda es más frecuente y recomendable reproducir los extranjerismos crudos en letra cursiva que escribirlos entrecomillados (salvo, claro está, en textos manuscritos o en soportes y tipos de letra que no admiten la cursiva)»(ORAE, 2010: 383). Por lo tanto, aunque formalmente existan dos procedimientos para marcar gráficamente un término extranjero en un texto escrito en español - la cursiva y las comillas-, su empleo no es equitativo o intercambiable, como acabamos de exponer. 
En cuanto a los latinismos encontramos mayor disparidad en las obras ortográficas. Así, mientras que en la edición anterior de $1999^{9}$ se les daba el tratamiento de voces españolas, ahora habrán de escribirse «en cursiva (o entre comillas) y sin acentos gráficos, ya que estos no existen en la escritura latina» (ORAE, 2010: 612). La $O R A E$ de 2010 introdujo, de esta manera, una novedad en este ámbito: la equiparación de su tratamiento ortográfico al resto de extranjerismos procedentes de lenguas vivas ${ }^{10}$. Por ejemplo, mientras que en 1999 exequátur se acentuaba conforme a las reglas ortográficas españolas (ORAE, 1999: 53); en 2010 se propone execuátur como voz plenamente adaptada o exequatur, con la grafía etimológica latina y sin acento (ORAE, 2010: 610).

Todos los libros de estilo consultados abogan por la corrección del lenguaje y dan preferencia al empleo de palabras y expresiones españolas sobre las extranjeras, incluidas las lenguas vernáculas. No obstante, reconocen el hecho de que hay realidades que solo es posible representar con un término extranjero o que son de difícil traducción, por lo que todos recogen excepciones. Para el tratamiento de estas voces encontramos principalmente partidarios de utilizar la cursiva como procedimiento de marcado. Un caso aparte lo constituyen los latinismos y las locuciones latinas, dado que todos los libros de estilo consultados que abordan el tema son anteriores a 2010, salvo el Libro del estilo urgente de la Agencia EFE publicado en 2011, y, por lo tanto, siguen las normas establecidas en las obra ortográfica de 1999.

- El Libro de estilo de El Mundo establece que las palabras o frases en otros idiomas «se identificarán siempre con el empleo de cursivas» (Libro de estilo de El Mundo, 1996: 80) y no recoge el empleo de las comillas como marca gráfica para los extranjerismos crudos. No comenta nada sobre los latinismos y las locuciones latinas.

- El Libro de estilo de $A B C$ diferencia entre extranjerismos de lenguas vernáculas y de otras lenguas pero en ambos casos indica que se escribirán en cursiva cuando vayan con su grafía original. No indica el uso de las comillas para resaltar gráficamente una voz extranjera. Sin embargo, «las locuciones y términos latinos que se usan habitualmente en castellano no se consideran extranjerismos y deben llevar tilde si les corresponde [...]. Se exceptúan los que forman parte de un tecnicismo o nombre científico (terminología internacional), que deben escribirse en cursiva en el texto» (Libro de estilo de $A B C, 2001:$ 12).

- El Libro de estilo Vocento considera que todas las voces extranjeras que aparezcan con la grafía original se escribirán en cursiva y no da indicaciones

\footnotetext{
${ }^{9}$ «Las voces y expresiones latinas usadas en nuestra lengua se acentuarán gráficamente de acuerdo con las reglas generales del español» (ORAE, 1999: 53).

${ }^{10}$ La Academia considera que el «carácter foráneo de esas voces debe marcarse gráficamente, como es habitual cuando se usan palabras o expresiones en otro idioma» (ORAE, 2010: 607).
} 
sobre el empleo de las comillas para resaltarlas tipográficamente. Asimismo, los latinismos no adaptados, ni admitidos por la Academia se escribirán en cursiva, así como también «las denominaciones latinas o latinizadas con que se representa la terminología internacional de animales y plantas» (Libro de estilo Vocento 2003: 106). Para las locuciones latinas, no obstante, indica que «lo más congruente es darles tratamiento pleno de voces españolas; deben escribirse, pues, en redonda (no de cursiva) [...] estén registradas o no en el Diccionario académico, cuando estén utilizadas como si se tratara de voces o términos españoles» (Libro de estilo Vocento, 2003: 106).

- El Libro de estilo de El País señala que las voces extranjeras «se escriben en cursiva [...] y, desde luego, con la acentuación, el género o los plurales que les corresponden en su idioma original» (Libro de estilo de El País, 2004: 32). Aunque es cierto que distingue el uso de las comillas para destacar un neologismo o un término no castellano, señala que para estos casos ha de emplearse la cursiva. En cuanto a las voces latinas determina, no obstante, que «se acentuarán de acuerdo a las leyes fonéticas para las voces castellanas - salvo que formen parte de nombres científicos - y se escribirán en cursiva - salvo que se trate de vocablos a castellanizados—》 (Libro de estilo de El País, 2004: 98).

- El Libro del estilo urgente de la Agencia EFE, aunque se centra fundamentalmente en cuestiones de fondo del estilo periodístico, recoge las principales novedades de la última edición de la ortografía académica e indica que los latinismos que son locuciones se escribirán «sin tilde y en cursiva» (Libro del estilo urgente de la Agencia EFE, 2011: 310).

Asimismo, también hemos consultado el manual Ortografía y ortotipografía del español actual de José Martínez de Sousa, por ser este autor un referente en cuestiones ortográficas y ortotipográficas. Así, dispone que «las voces extranjeras que no sean cita no se escriben con comillas, sino de cursiva (o subrayadas una sola vez en lo manuscrito o lo mecanográfico)» (Martínez de Sousa, 2004: 392d). Por el contrario, no considera extranjeras «las palabras o locuciones latinas, estén admitidas por la Academia o no. Por consiguiente, se escribirán de redondo [...] y deben tildarse a la española» (Martínez de Sousa, 2004: 509-510). Sin embargo, «se escriben con cursiva los nombres latinos o latinizados de animales, plantas o virus (nombres científicos o específicos)» (Martínez de Sousa, 2004: 505).

A pesar de que, como hemos visto anteriormente, tanto las obras académicas como los manuales de estilo son partidarios del marcado mediante la cursiva, encontramos un caso excepcional en los titulares y ladillos de la prensa escrita. Dado que estos tienen unas normas ortotipográficas que difieren de las del resto del cuerpo del texto, se les concede un carácter especial; así, según la Academia, «en los titulares de prensa, la cursiva puede ser reemplazada en este uso por comillas simples: Messi consigue su cuarto 'hat-trick' esta temporada» (ORAE, 2010: 383). Este hecho también se recoge 
en el Libro de estilo de El País (2004: 126): «en los titulares y en los ladillos compuestos en línea aparte se escribirán entre comillas simples aquellas palabras que [...] hubieran de ir en cursiva» y el Libro de estilo de ABC. Sin embargo, en este último leemos el ejemplo: La sombra del «impeachment» (Libro de estilo de ABC, 2001: 78), del que deducimos que se prefiere el empleo de las comillas angulares.

\section{ANÁLISIS CUANTITATIVO Y CUALITATIVO}

\subsection{Corrección ortográfica, ortotipográfica y lexicográfica en cuanto al tratamiento de los extranjerismos}

Como se dijo anteriormente, el objetivo principal de nuestro trabajo es analizar el grado de cumplimiento de la norma académica ortográfica y ortotipográfica en cuanto al tratamiento de los extranjerismos crudos en la prensa escrita española; como observamos en la tabla 1, la distribución de las voces foráneas según tengan en cuenta la norma establecida por la Academia se realiza del siguiente modo:

\begin{tabular}{|c|c|c|}
\cline { 2 - 3 } \multicolumn{1}{c|}{} & $\mathrm{N}$ & $\%$ \\
\hline Sigue la norma académica & 782 & 71.7 \\
\hline No sigue la norma ortográfica & 290 & 26.6 \\
\hline $\begin{array}{c}\text { No sigue la norma } \\
\text { ortotipográfica }\end{array}$ & 2 & 0.2 \\
\hline Es una forma híbrida & 16 & 1.5 \\
\hline TOTAL & 1090 & 100.0 \\
\hline
\end{tabular}

Tabla 1. Cumplimiento de la norma académica ortográfica y ortotipográfica. Frecuencias absolutas

Esta tabla muestra, en primer lugar, que el $71.7 \%$ de los extranjerismos recogidos se encuentran marcados como voces ajenas, esto es: con cursiva o entre comillas, frente a un $28.3 \%$ que no cumple dicha norma. Por lo tanto, se refuta nuestra hipótesis de partida, que consiste en que la prensa escrita española sigue las normas estipuladas por la $O R A E$ y mantiene un alto grado de corrección. En segundo lugar, observamos que el grado de incumplimiento de la norma ortotipográfica es prácticamente anecdótico, con un $0.2 \%$ del total; así como también lo son los casos de las formas híbridas con un porcentaje del $1.5 \%$. 
Si consideramos incorrectas las tres últimas opciones, que se contraponen al cumplimiento de la norma académica ortográfica, podemos reagruparlas en una sola variante: «no sigue la norma académica», para un mejor análisis posterior. La tabla (tabla 2) quedaría entonces de la siguiente manera:

\begin{tabular}{|c|c|c|}
\cline { 2 - 3 } \multicolumn{1}{c|}{} & $\mathrm{N}$ & $\%$ \\
\hline Sigue la norma académica & 782 & 71.1 \\
\hline No sigue la norma académica & 308 & 28.3 \\
\hline TOTAL & 1090 & 100.0 \\
\hline
\end{tabular}

Tabla 2. Cumplimiento de la norma académica ortográfica. Frecuencias absolutas

Nuestro análisis también pretende abordar el parámetro lexicográfico. En general, podemos afirmar que el porcentaje de casos para los que no existe ningún término patrimonial en español es elevado, $73.3 \%$, frente al $26.7 \%$ de extranjerismos crudos que no se adecuan a la norma lexicográfica, es decir, para los que existe una voz patrimonial que no se emplea en su lugar (tabla 3):

\begin{tabular}{|c|c|c|}
\cline { 2 - 3 } \multicolumn{1}{c|}{} & $\mathrm{N}$ & $\%$ \\
\hline $\begin{array}{c}\text { Existe un término alternativo o } \\
\text { equivalente }\end{array}$ & 291 & 26.7 \\
\hline $\begin{array}{c}\text { No existe ningún término } \\
\text { alternativo ni equivalente }\end{array}$ & 799 & 73.3 \\
\hline TOTAL & 1090 & 100.0 \\
\hline
\end{tabular}

Tabla 3. Cumplimiento de la norma académica lexicográfica. Frecuencias absolutas

Si cruzamos los casos de nuestras dos variables dependientes, «norma ortográfica» y «norma lexicográfica», comprobamos qué porcentaje de los extranjerismos crudos hallados en nuestro corpus incumplen al mismo tiempo los dos criterios de corrección, es decir, son voces foráneas que no se encuentran marcadas gráficamente y para las que existe término patrimonial que no ha sido empleado en su lugar: 


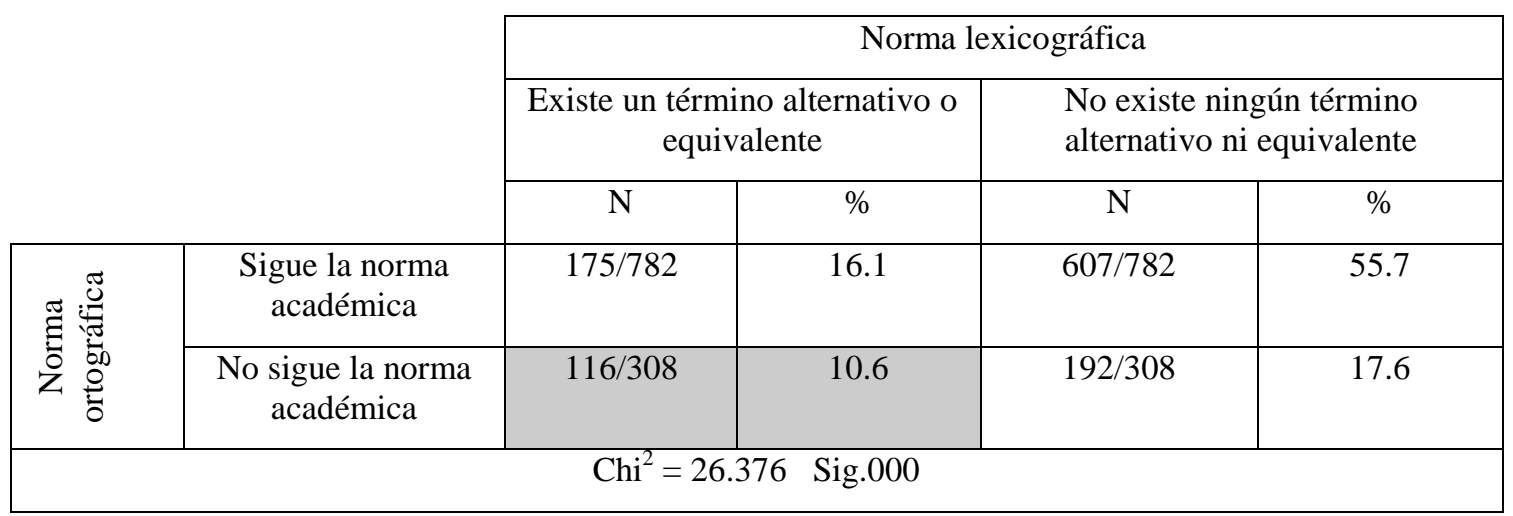

Tabla 4. Incumplimiento de la norma académica ortográfica y lexicográfica

Así, la tabla nos indica que tan solo un $10.6 \%$ de todos los extranjerismos crudos incumplen simultáneamente la norma ortográfica y lexicográfica, lo que supone un porcentaje reducido. Sin embargo, encontramos que el $33.7 \%$ de casos incurren en error en cuanto a una de las dos normas; lo que deja un porcentaje que apenas supera la media $(55.7 \%)$ de extranjerismos escritos correctamente de acuerdo con ambas normas académicas, dato que resulta preocupante.

\section{2. $\quad$ Publicaciones en las que aparecen los extranjerismos crudos}

Del total de los 1090 extranjerismos que hemos recogido en nuestra base de datos, observamos que la distribución de los mismos según la publicación se realiza de la siguiente manera (tabla 5):

\begin{tabular}{|c|c|c|}
\cline { 2 - 3 } \multicolumn{1}{c|}{} & $\mathrm{N}$ & $\%$ \\
\hline El País & 130 & 11.9 \\
\hline Público & 48 & 4.4 \\
\hline ABC & 115 & 20.3 \\
\hline El Mundo & 221 & 15.3 \\
\hline Ideal & 167 & 10.7 \\
\hline Muy Interesante & 117 & 12.2 \\
\hline Geo & 133 & 6.1 \\
\hline Le Monde Diplomatique & 67 & 8.4 \\
\hline Actualidad Económica & 92 & 100.0 \\
\hline TOTAL & 1090 & \\
\hline
\end{tabular}

Tabla 5. Distribución de los extranjerismos por publicación. Frecuencias absolutas 
Como podemos observar, el reparto de los extranjerismos es bastante dispar: $E l$ Mundo es la publicación que más voces extranjeras alberga, con un porcentaje de $20.3 \%$ del total, mientras que las tres publicaciones con el porcentaje más bajo, que son Público, Le Monde Diplomatique y Actualidad Económica, no alcanzan siquiera dicho porcentaje, sumando entre las tres un total de $18.9 \%$. El resto de publicaciones tienen unos porcentajes similares que se mantienen en la franja del 10 al $15 \%$.

Una vez analizadas estas cuestiones, cabe preguntarse, en primer lugar, cuál es la publicación más incorrecta desde el punto de vista ortográfico (gráfico 1):

Gráfico 1

Incumplimiento de la norma ortográfica según publicación

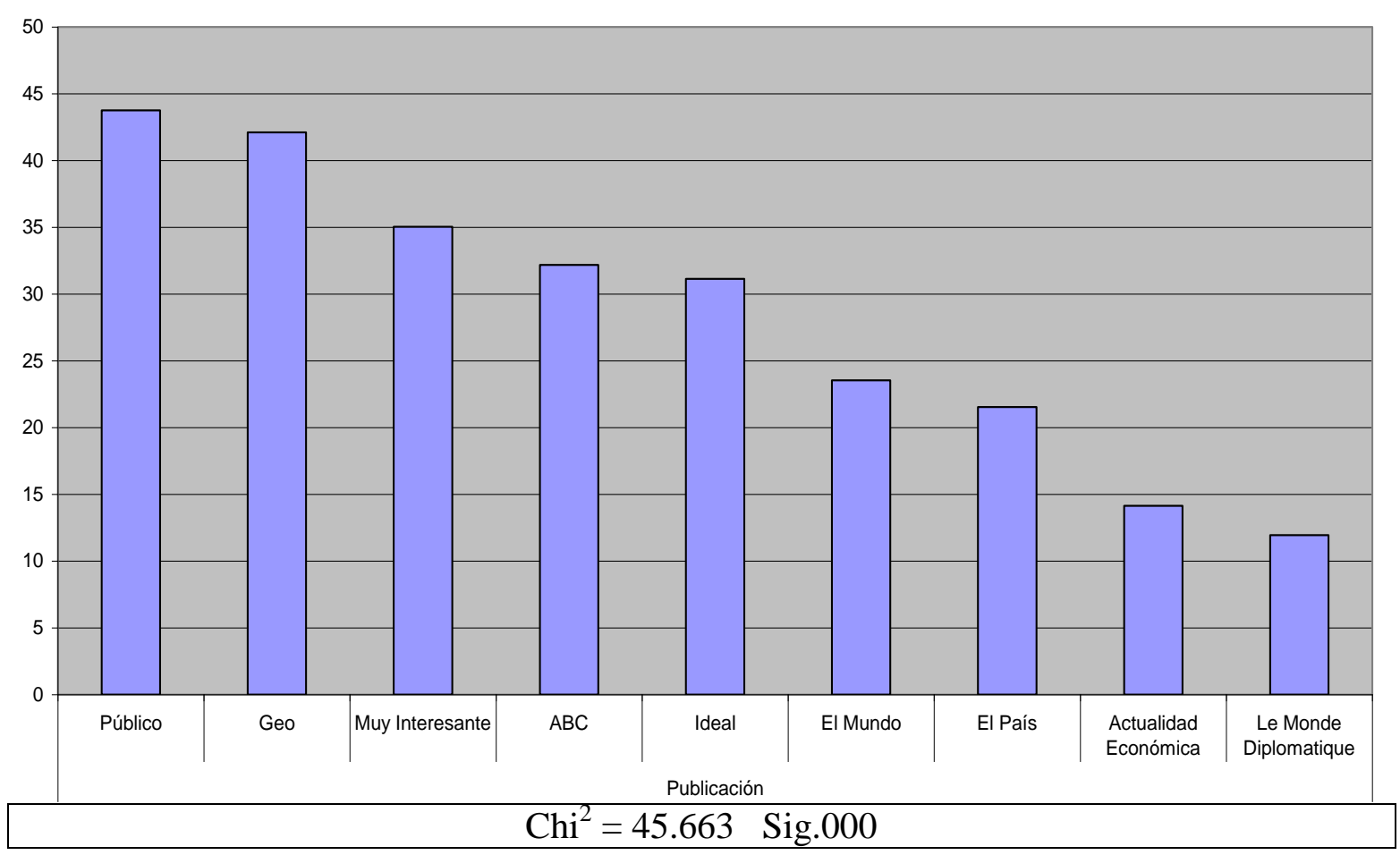

El gráfico revela que las dos publicaciones más incorrectas son el periódico Público, que no cuenta con manual de estilo, con un $43.8 \%$ de los extranjerismos no marcados, y la revista Geo, con un $42.1 \%$; seguidas de cerca por la revista Muy Interesante, con un $35.0 \%$. Estos datos son bastante alarmantes, ya que reflejan un alto grado de incumplimiento de la norma ortográfica en cuanto al tratamiento de los extranjerismos crudos. Por otro lado, observamos que las publicaciones más correctas son las revistas Actualidad Económica y Le Monde Diplomatique. 
Y, en segundo lugar, cuál es la publicación más incorrecta teniendo en cuenta el parámetro lexicográfico (gráfico 2), es decir, qué publicación utiliza más voces extranjeras para las que existen términos patrimoniales y, por lo tanto, no sigue las normas establecidas en el $D P D$ :

Gráfico 2

Incumplimiento de la norma lexicográfica según publicación

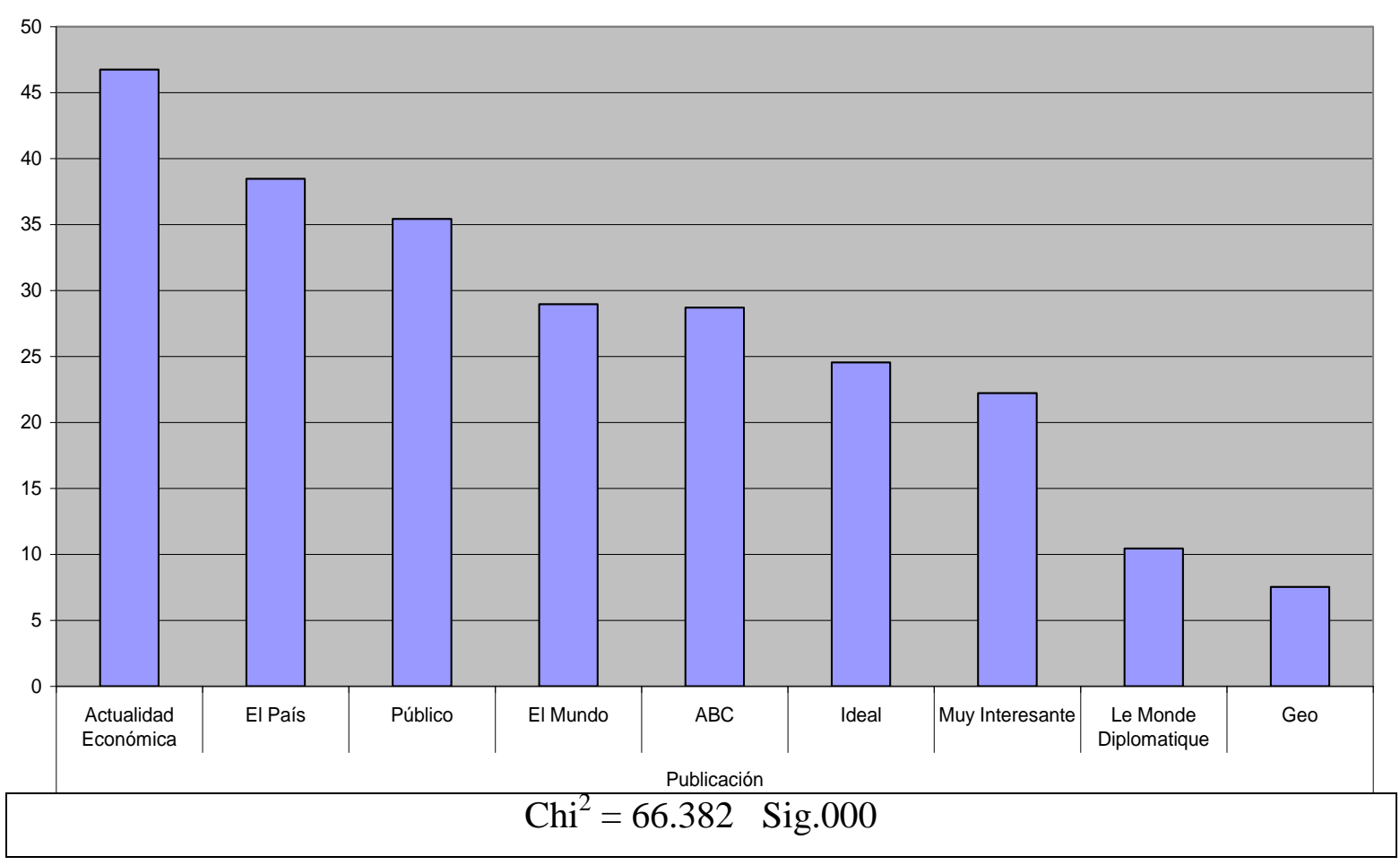

Observamos, pues, que la publicación que más desatiende este criterio es Actualidad Económica, con un $46.7 \%$; si bien era esta una de las publicaciones más correctas en cuanto al tratamiento ortográfico de los extranjerismos crudos, presenta un porcentaje extremadamente elevado de incorrección lexicográfica. En segundo y tercer lugar encontramos los periódicos El País y Público, con porcentajes del $38.5 \%$ y del $35.4 \%$, respectivamente, de voces extranjeras para las que existe una alternativa española. Entre las publicaciones más correctas se sitúan Geo, que contaba con un alto porcentaje de incorrección ortográfica, y Le Monde Diplomatique.

\section{3. $\quad$ Origen de los extranjerismos crudos}

Con la variable «origen del extranjerismo», queremos reflejar cuáles son aquellos extranjerismos crudos que tienen más presencia en la prensa. Dado que el origen de los 
extranjerismos crudos extraídos en nuestro corpus es muy variado, hemos destacado las tres lenguas que más nos interesan, el latín, el inglés y el francés, y hemos reagrupado las demás en tres variantes: «lenguas vernáculas», «demás lenguas europeas»y «lenguas africanas, asiáticas y oceánicas».

La siguiente tabla (tabla 6) revela el predominio de los anglicismos, con un $68.5 \%$ de presencia en nuestro corpus, lo que se debe a la influencia del mundo anglosajón y, por ende, del inglés como lengua de comunicación internacional en ámbitos como la economía, las nuevas tecnologías y la ciencia, entre otros. Asimismo, observamos que los latinismos, situados en segundo lugar con un $11.2 \%$, tienen también una importante presencia en la lengua española, quizá a causa tanto de necesidades expresivas como del prurito culto de los periodistas ${ }^{11}$. La tercera lengua con más representación es el francés, con un $5.4 \%$. Por otro lado, la presencia de las lenguas vernáculas es relativamente escasa, llegando a contar entre el catalán, el vasco y el gallego con solo un $4.1 \%$ del total. Por último, observamos que la aparición de voces pertenecientes a lenguas minoritarias o a lenguas lejanas y desconocidas, como las asiáticas, es puntual y, probablemente, responda a su mención en alguna noticia o algún reportaje.

\begin{tabular}{|c|c|c|}
\cline { 2 - 3 } \multicolumn{1}{c|}{} & $\mathrm{N}$ & $\%$ \\
\hline Voz inglesa & 747 & 68.5 \\
\hline Voz latina & 122 & 11.2 \\
\hline Voz francesa & 59 & 5.4 \\
\hline Lenguas vernáculas & 44 & 4.1 \\
\hline Demás lenguas europeas & 56 & 5.2 \\
\hline $\begin{array}{c}\text { Lenguas africanas, asiáticas y } \\
\text { oceánicas }\end{array}$ & 62 & 5.6 \\
\hline TOTAL & 1090 & 100.0 \\
\hline
\end{tabular}

Tabla 6. Origen de los extranjerismos. Frecuencias absolutas

En general, la distribución de los extranjerismos crudos dependiendo de la publicación se realiza de la siguiente manera (gráfico 3):

${ }^{11}$ Como indica la $\operatorname{ORAE}$ (2010: 605) el latín es «la lengua culta por excelencia, de la que las distintas lenguas europeas, entre ellas el español, toman prestados términos para cubrir las nuevas necesidades expresivas que van surgiendo a medida que esas lenguas se convierten en vehículos de expresión en todos los ámbitos de la ciencia y la cultura. A menudo la incorporación de cultismos responde, simplemente, al prestigio de los términos latinos cultos frente a las voces patrimoniales, a algunas de las cuales llegan incluso a desplazar por completo en el uso». 
Gráfico 3

Origen de los extranjerismos crudos utilizados en las publicaciones

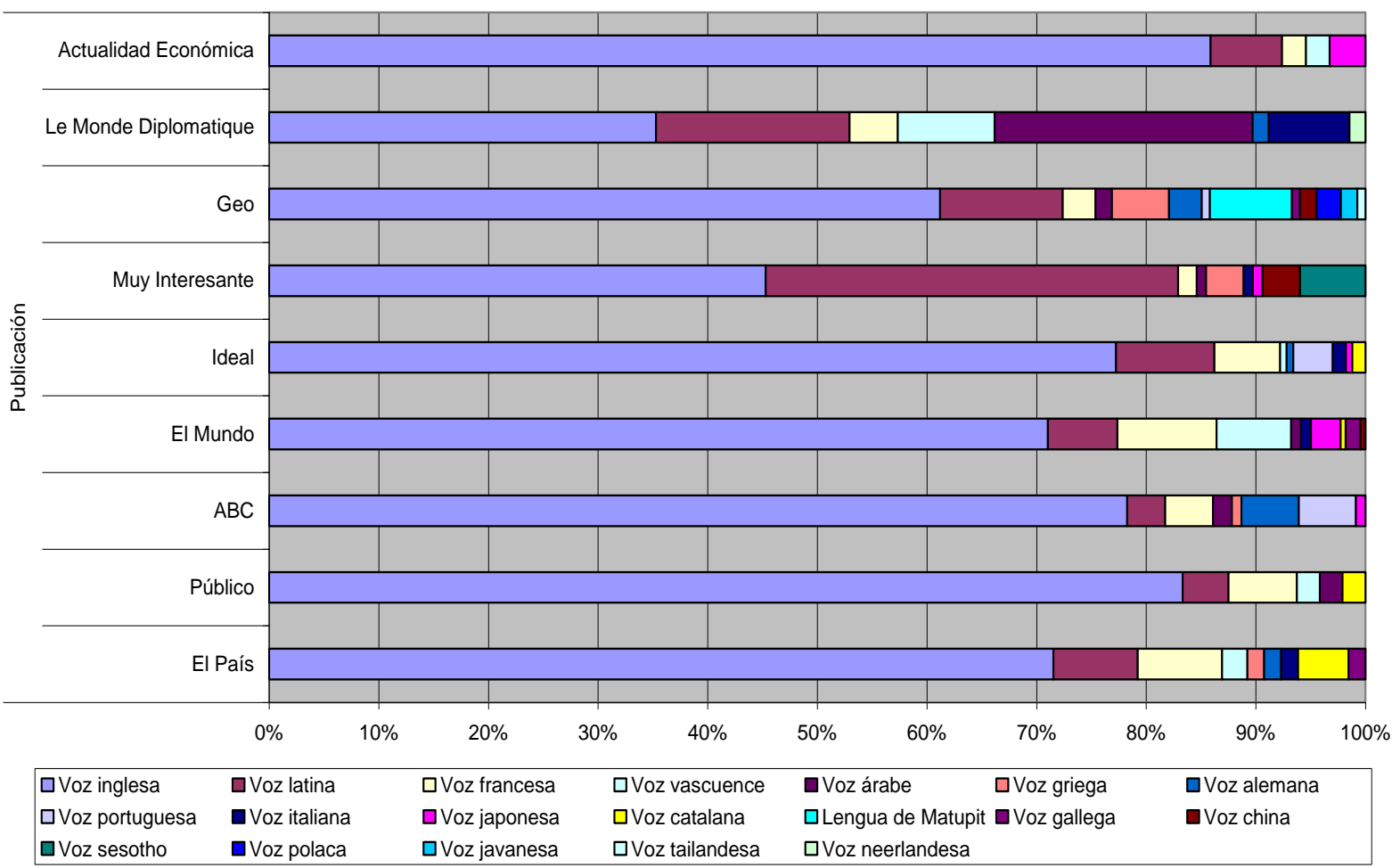

$$
\mathrm{Chi}^{2}=693.255 \text { Sig.000 }
$$

Observando el gráfico podemos advertir varias cosas. En primer lugar, que la presencia mayoritaria de los anglicismos es un denominador común en todas las publicaciones. Asimismo, también todas incluyen, aunque en menor medida, voces latinas, que responden tanto al prurito culto, como a la necesidad de establecer nueva terminología específica en los ámbitos científico y técnico, que recurren a esta lengua clásica para crear neología. A esta última razón atribuimos la gran presencia de latinismos en la revista Muy Interesante, de divulgación científica y técnica. Las voces francesas también se encuentran presentes en todas las publicaciones. En segundo lugar, que, salvo el periódico $A B C$, todos los periódicos recogen, de alguna manera, voces en lenguas vernáculas. En tercer lugar, que la presencia de extranjerismos contenidos en las publicaciones de otras procedencias es bastante arbitraria y, seguramente, se deba a la información comprendida en las mismas. Así, por ejemplo, aunque haya muchas voces árabes en Le Monde Diplomatique (con un $23.5 \%$ del total de sus voces extranjeras), El 
País e Ideal, no recogen ninguna; o la incorporación de voces sesotho solo se ve en la revista Muy Interesante.

Otra cuestión de interés, en este sentido, es ver qué tratamiento se les da dependiendo del origen que tengan (tabla 7). Tendemos a pensar que las lenguas más cercanas a nosotros, como las lenguas vernáculas o el latín, muchas veces no son consideradas tan extrañas o exóticas como lo pudieran ser otras; o que extranjerismos procedentes del inglés y el francés pasan desapercibidos por su uso extendido:

\begin{tabular}{|c|c|c|}
\cline { 2 - 3 } \multicolumn{1}{c|}{} & \multicolumn{2}{c|}{ No sigue la norma académica } \\
\hline Voz latina & $\mathrm{N}$ & $\%$ \\
\hline Voz inglesa & $15 / 122$ & 12.3 \\
\hline Voz francesa & $244 / 747$ & 32.7 \\
\hline Lenguas vernáculas & $12 / 59$ & 20.3 \\
\hline Demás lenguas europeas & $17 / 56$ & 13.6 \\
\hline $\begin{array}{c}\text { Lenguas africanas, asiáticas y } \\
\text { oceánicas }\end{array}$ & $14 / 62$ & 22.6 \\
\hline TOTAL & $308 / 1090$ & $28.3 / 100.0$ \\
\hline \multicolumn{2}{|c|}{$\mathrm{Chi}^{2}=26.527$} & Sig. 000 \\
\hline
\end{tabular}

Tabla 7. Incumplimiento de la norma ortográfica según el origen de los extranjerismos

Cabe destacar que el grado de incorrección que presentan los latinismos es muy bajo, a pesar de que la nueva $O R A E$ incorpora una gran novedad al respecto: la equiparación de su tratamiento ortográfico al resto de voces extranjeras; y de que los libros de estilo de los periódicos consultados no recojan dicha novedad, ya que son anteriores al 2010. Asimismo, el porcentaje de incumplimiento normativo de las lenguas vernáculas también es muy bajo. Por otro lado, y aunque, en proporción, el inglés presenta un grado de corrección notable, nos parece alarmante la cantidad de voces (244 en total, cifra que dobla la cantidad de voces latinas encontradas en todo nuestro corpus) que no se ajustan a la norma académica y no se resaltan como ajenas.

Asimismo, otro aspecto que atender es el hecho de si el origen de las voces extranjeras influye en la variable lexicográfica. De todos los extranjerismos crudos encontrados, solo los anglicismos y los galicismos parecen encontrar equivalencias en nuestro idioma, mientras que el resto de voces extranjeras parecen haber sido empleadas por necesidad expresiva, como señala la $O R A E$ (2010: 599) bien sea por prurito culto, para aportar color local o para aprovechar su capacidad de aludir al origen de su referente o al ámbito cultural al que pertenece. Así, como muestra la tabla 8 hemos simplificado las variantes en tres grupos: 


\begin{tabular}{|c|c|c|}
\cline { 2 - 3 } \multicolumn{1}{c|}{} & \multicolumn{2}{c|}{$\begin{array}{c}\text { Existe un término alternativo o } \\
\text { equivalente }\end{array}$} \\
\cline { 2 - 3 } \multicolumn{1}{c|}{} & $\mathrm{N}$ & $\%$ \\
\hline Anglicismos & 276 & 36.9 \\
\hline Galicismos & 15 & 25.4 \\
\hline Otros & 0 & 0.0 \\
\hline TOTAL & $291 / 1090$ & $26.7 / 100.0$ \\
\hline \multicolumn{2}{|c|}{$\mathrm{Chi}^{2}=143.143$} & Sig. 000 \\
\hline
\end{tabular}

Tabla 8. Incumplimiento de la norma lexicográfica según el origen de los extranjerismos

Resulta llamativo el abundante número de voces inglesas, 276 en total que suponen el $36.9 \%$ de las encontradas, para las cuales se recoge una alternativa patrimonial española, que, sin embargo, no ha sido utilizada en su lugar. Cabe preguntarse, pues, si la preferencia por el empleo de voces inglesas en los textos escritos en español, ignorando, así, las recomendaciones académicas, se debe a la hegemonía del inglés como lengua dominante en la comunicación internacional y es fruto del mimetismo lingüístico hacia esta lengua de prestigio.

\subsection{Categoría morfológica de los extranjerismos crudos}

Otra de nuestras variables tenía como función analizar el tipo de palabras extranjeras que incorporamos de manera preferente a nuestro discurso (tabla 9):

\begin{tabular}{|c|c|c|}
\cline { 2 - 3 } \multicolumn{1}{c|}{} & $\mathrm{N}$ & $\%$ \\
\hline Sustantivo & 784 & 71.9 \\
\hline Locución & 220 & 20.2 \\
\hline Adjetivo & 76 & 7.0 \\
\hline Adverbio & 4 & 0.4 \\
\hline Verbo & 2 & 0.2 \\
\hline Pronombre & 1 & 0.1 \\
\hline Preposición & 3 & 0.3 \\
\hline TOTAL & 1090 & 100.0 \\
\hline
\end{tabular}

Tabla 9. Tipo de extranjerismo. Frecuencias absolutas 
Como ya suponíamos, fundamentalmente incorporamos sustantivos, que alcanzan un porcentaje del $71.9 \%$ de las voces encontradas. No obstante, observamos que también hay cierta presencia de locuciones $(20.2 \%)$ y, en menor medida, de adjetivos, con un porcentaje del $7.0 \%$. Las demás categorías morfológicas, aunque presentes en menor medida, no adquieren tanta importancia como las anteriores.

Al analizar el grado de corrección ortográfica que presentan los extranjerismos crudos dependiendo de su categoría morfológica (tabla 10), advertimos que, aunque, en general, todos cumplen la norma, con excepción de las preposiciones, los sustantivos y los adverbios presentan un mayor porcentaje de incorrección:

\begin{tabular}{|c|c|c|}
\cline { 2 - 3 } \multicolumn{1}{c|}{} & \multicolumn{2}{c|}{ No sigue la norma académica } \\
\cline { 2 - 3 } \multicolumn{1}{c|}{} & $\mathrm{N}$ & $\%$ \\
\hline Sustantivo & $260 / 784$ & 33.2 \\
\hline Locución & $35 / 220$ & 15.9 \\
\hline Adjetivo & $8 / 76$ & 10.5 \\
\hline Adverbio & $2 / 4$ & 50.0 \\
\hline Verbo & $0 / 2$ & 0.0 \\
\hline Pronombre & $3 / 3$ & 0.0 \\
\hline Preposición & $308 / 1090$ & $28.3 / 100.0$ \\
\hline TOTAL & Sig. 000 \\
\hline
\end{tabular}

Tabla 10. Incumplimiento de la norma ortográfica según tipo de extranjerismo

Si tenemos en cuenta el criterio lexicográfico (tabla 11), observamos que los adjetivos adquieren el porcentaje más elevado de incorrección en cuanto a la norma lexicográfica, a pesar de que cumplen en un $89.5 \%$ la directriz ortográfica; y que palabras como verbos, pronombres o locuciones, a diferencia de los sustantivos, no suelen encontrar o rara vez encuentran equivalencia española: 


\begin{tabular}{|c|c|c|}
\cline { 2 - 3 } \multicolumn{1}{c|}{} & \multicolumn{2}{c|}{$\begin{array}{c}\text { Existe un término alternativo o } \\
\text { equivalente }\end{array}$} \\
\cline { 2 - 3 } \multicolumn{1}{c|}{} & $\mathrm{N}$ & $\%$ \\
\hline Sustantivo & $239 / 784$ & 30.5 \\
\hline Locución & $13 / 220$ & 5.9 \\
\hline Adjetivo & $36 / 76$ & 47.7 \\
\hline Adverbio & $2 / 4$ & 50.0 \\
\hline Verbo & $0 / 2$ & 0.0 \\
\hline Pronombre & $0 / 1$ & 0.0 \\
\hline Preposición & $1 / 3$ & 33.3 \\
\hline TOTAL & $291 / 1090$ & $26.7 / 100.0$ \\
\hline Chi $^{2}=73.192$ & Sig. 000 \\
\hline
\end{tabular}

Tabla 11. Incumplimiento de la norma lexicográfica según tipo de extranjerismo

\section{5. $\quad$ Procedimiento de marcado de los extranjerismos crudos}

Pasamos ahora a analizar el procedimiento para el marcado de los extranjerismos crudos. En la tabla 12 observamos que, entre las voces resaltadas gráficamente, predomina el empleo de la cursiva $(55.3 \%)$, por lo que se cumple en gran medida la norma ortográfica académica, que establece la utilización preferente de la misma para marcar las voces foráneas:

\begin{tabular}{|c|c|c|}
\cline { 2 - 3 } \multicolumn{1}{c|}{} & $\mathrm{N}$ & \% \\
\hline No marcado & 301 & 27.6 \\
\hline Cursiva & 603 & 35.3 \\
\hline Redonda con comillas españolas & 43 & 0.3 \\
\hline Redonda con comillas inglesas & 3 & 12.2 \\
\hline Redonda con comillas simples & 133 & 0.1 \\
\hline Redonda con distintas comillas & 1 & 0.1 \\
\hline Cursiva con comillas simples & 1 & 0.1 \\
\hline Cursiva con comillas inglesas & 1 & 0.3 \\
\hline Redonda en negrita & 3 & 0.1 \\
\hline Solo una comilla & 1 & 100.0 \\
\hline TOTAL & 1090 & \multicolumn{2}{|c|}{} \\
\hline
\end{tabular}

Tabla 12. Procedimiento para marcado. Frecuencias absolutas 
Otra conclusión que podemos extraer de la tabla anterior es que, aunque la $O R A E$ indica que en los textos impresos se utilizarán preferentemente las comillas latinas o españolas («»), en segundo lugar las inglesas (" ") y, por último, las simples (" '): "Antonio me dijo: "Vaya 'cacharro' que se ha comprado Julián”" (ORAE, 2010: 380); parece que la prensa escrita desatiende este orden de preferencia y opta por el marcado de los extranjerismos mediante el empleo de las comillas simples en primer lugar, con un $12.2 \%$, frente al $3.9 \%$ de las comillas españolas y el $0.3 \%$ de las comillas inglesas. Asimismo, si atendemos el hecho de la escritura entrecomillada de los extranjerismos crudos en este apartado y tenemos en cuenta la norma académica, podemos considerar que el uso de este resalte gráfico en publicaciones impresas no supone una incorrección, si bien un desvío de la norma ortográfica, que establece su empleo en los textos manuscritos. Así, aunque la $\operatorname{ORAE}$ (2010: 383) indica que entre las funciones de las comillas se encuentran las de resaltar que una palabra o expresión es impropia, vulgar, procede de otra lengua o se utiliza irónicamente o con sentido especial; sin embargo, como ya recogimos en el $\S 2$, también establece que «en textos impresos en letra redonda es más frecuente y recomendable reproducir los extranjerismos crudos en letra cursiva que escribirlos entrecomillados (salvo, claro está, en textos manuscritos o en soportes y tipos de letra que no admiten la cursiva» (ORAE, 2010: 383). No obstante, y puesto que la Academia solo recomienda el uso de la cursiva ante el del entrecomillado, podemos concluir considerando este procedimiento normativo, ya que lo fundamental es que se han marcado gráficamente las voces extranjeras, resaltando, de esta manera, su condición de ajenas.

Por otro lado, como muestra la tabla, existe un porcentaje bastante bajo que incurre en error en cuanto al marcado de las voces foráneas, por desconocimiento de la norma ortográfica y ortotipográfica, que están recogidas en las opciones «redonda en negrita», y «cursiva con comillas simples» y «cursiva con comillas inglesas», respectivamente.

Por último, queremos explicar dos variantes de la tabla: «redonda con distintas comillas» y «solo una comilla». En el primer caso, hemos tenido en cuenta la coincidencia de comillas simples e inglesas de cierre en el siguiente ejemplo: "A todo vasco le tiene que ilusionar ser 'lehendakari" (El País, 22/1/2012). Aunque la Academia no se ha pronunciado al respecto sobre este tema, encontramos dos opiniones contradictorias: por un lado, el Libro de estilo de El País (2004: 126) establece que «en caso de tener que escribir estos dos tipos de comillas juntos, por coincidir al principio o al final de la cita, se suprimirán las comillas simples» ${ }^{12}$; por otro, Martínez de Sousa (2004: 397) señala que no es correcto en ningún caso suprimir la comilla de cierre cuando coinciden comillas simples e inglesas y que el encuentro se resolverá separándolas ligeramente. Dado que el ejemplo se ha observado en el periódico El País, podemos concluir diciendo que es correcto puesto que sigue su propia norma. En el

${ }^{12}$ Aquí hemos de señalar que este manual determina que nunca se utilizarán las comillas angulares en el periódico y que «cuando dentro de un entrecomillado vaya otro, el segundo se marcará con comillas simples» (Libro de estilo de El País, 2004: 126).

NORMAS. REVISTA DE ESTUdIOS LINGÜÍSTICOS HISPÁNICOS, NÚMERO 2 (AÑO 2012):

http://www.uv.es/normas

(ISSN 2174-7245) 
segundo caso, la supresión de una de las dos comillas se trata de una errata y, por lo tanto, también lo podemos considerar correcto.

Para observar la preferencia de cada publicación por uno u otro procedimiento de marcado hemos elaborado el gráfico 4, en el que podemos observar que todas las publicaciones comparten el empleo de la cursiva como procedimiento de marcado; así como también que todas cometen errores y no resaltan de manera gráfica algunos extranjerismos crudos.

Otro dato significativo es que el empleo de comillas simples está bastante extendido entre todas las publicaciones, salvo en las revistas Geo y Muy Interesante, que no lo utilizan.

Llamativo es, asimismo, el hecho de que tanto el periódico $A B C$, como el periódico Ideal, antepongan a la cursiva el marcado mediante comillas españolas y comillas simples, respectivamente; y que, a pesar de que ambos diarios pertenecen al grupo Vocento, tengan preferencia por distintos tipos de comillas:

\section{Gráfico 4}

Procedimiento para el marcado según la publicación

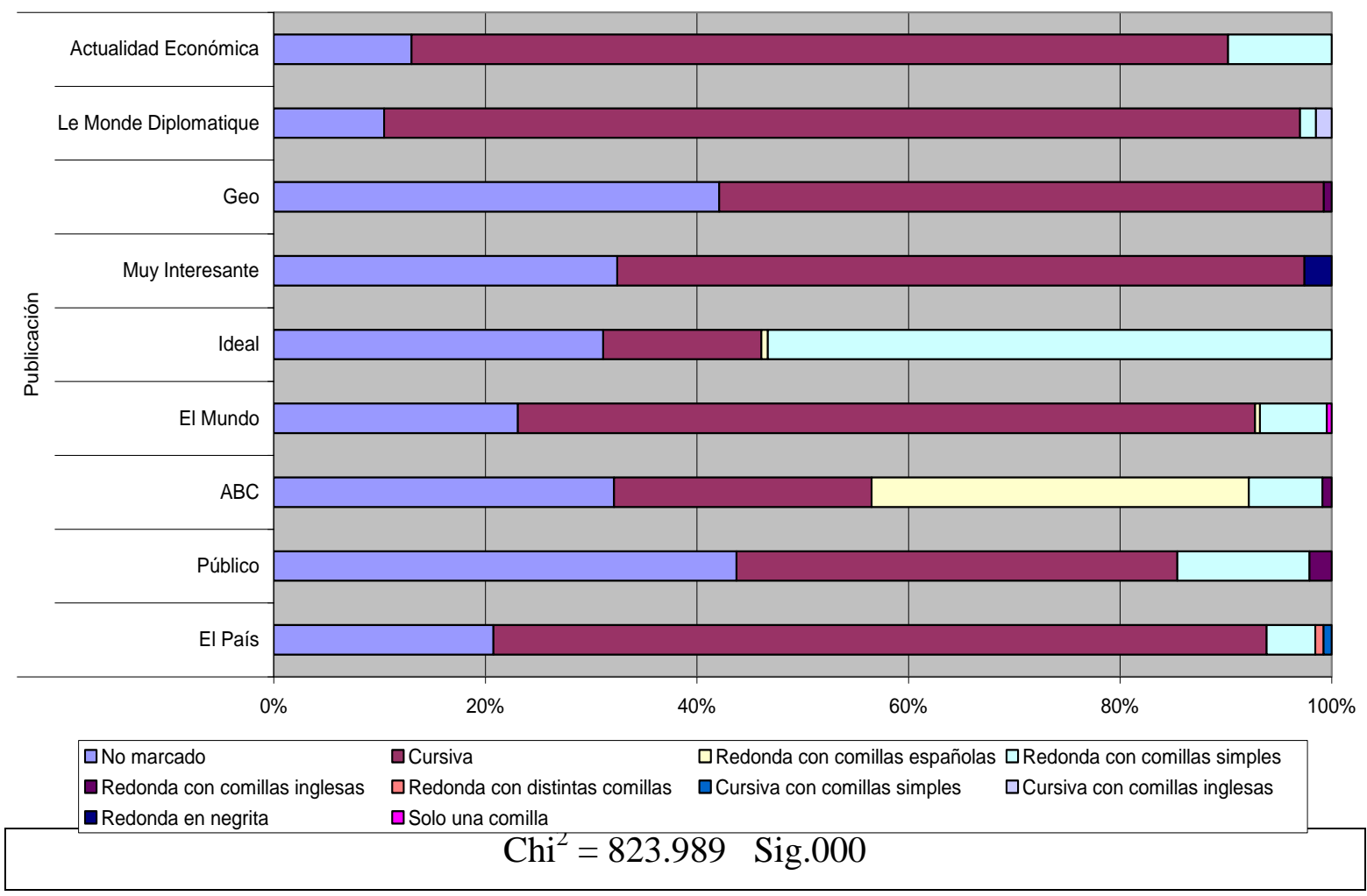


Finalmente, si simplificamos todas las posibilidades contempladas anteriormente para marcar los extranjerismos crudos en tres grupos: «voces no marcadas»; «voces marcadas según la norma académica», entre las que consideraríamos todas aquellas que han sido marcadas teniendo en cuenta la norma académica, así como también las opciones «redonda con distintas comillas»y «solo una comilla»; y «voces marcadas erróneamente», por desconocimiento de la norma académica; obtenemos la siguiente tabla (tabla 13), que nos revela que hay mayoría de voces resaltadas gráficamente (72.4\%), frente a las que no han sido destacadas como extranjeras en los textos escritos en español. Además, vemos que el grado de corrección en cuanto al procedimiento de marcado, con un $71.9 \%$, es muy elevado:

\begin{tabular}{|c|c|c|}
\cline { 2 - 3 } \multicolumn{1}{c|}{} & $\mathrm{N}$ & $\%$ \\
\hline Voces no marcadas & 301 & 27.6 \\
\hline $\begin{array}{c}\text { Voces marcadas según la norma } \\
\text { académica }\end{array}$ & 784 & 0.5 \\
\hline Voces marcadas erróneamente & 5 & 100.0 \\
\hline TOTAL & 1090 & 0 \\
\hline
\end{tabular}

Tabla 13. Tipos de marcado. Frecuencias absolutas

Para ver la distribución de los tipos de marcado según las diferentes publicaciones, hemos elaborado el gráfico 5: 
Gráfico 5

Tipos de marcado según la publicación

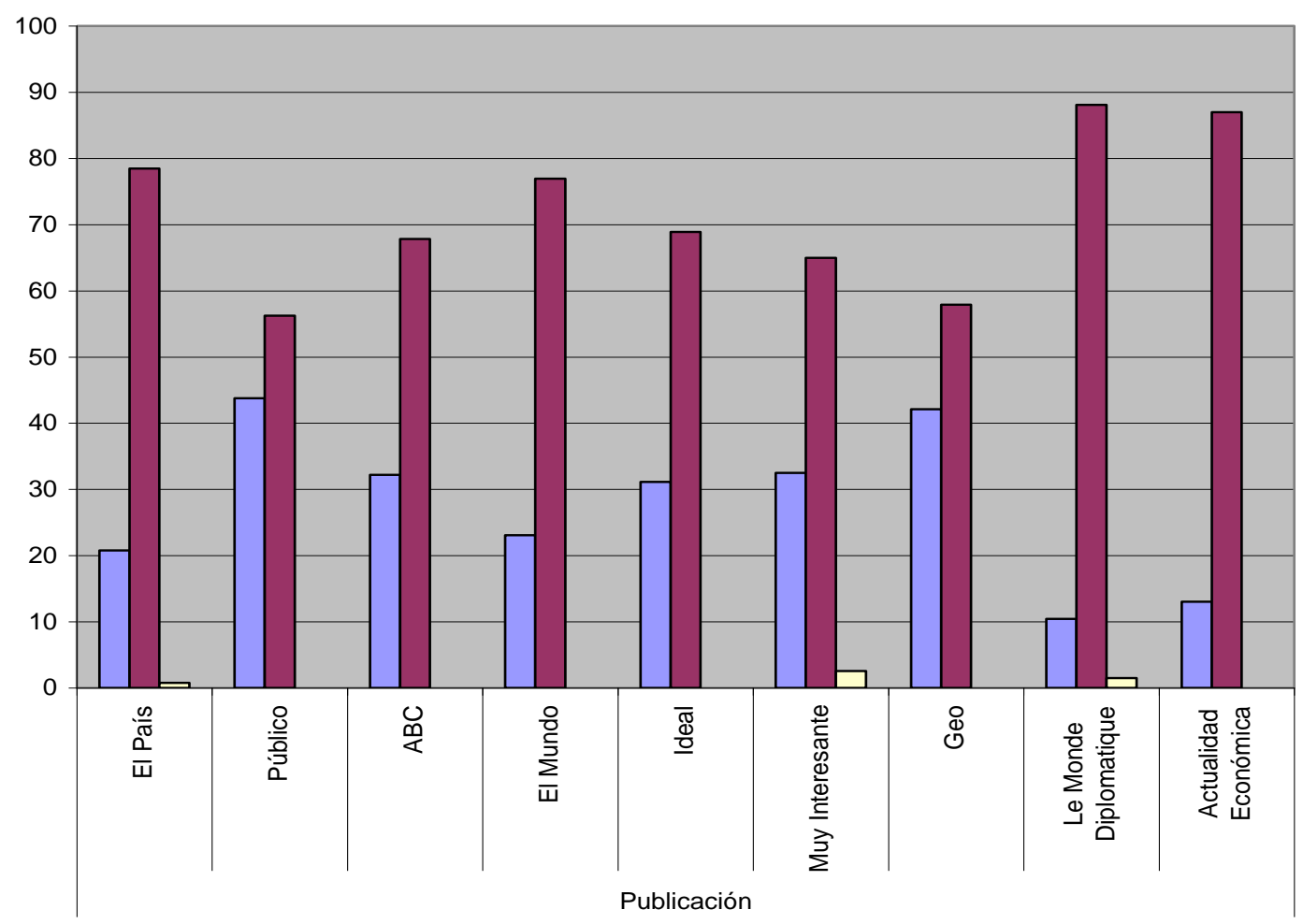

$\square$ Voces no marcadas

$\square$ Voces marcadas según la norma académica

$\square$ Voces marcadas erróneamente

$$
\mathrm{Chi}^{2}=65.445 \text { Sig.000 }
$$

Los datos que revela este gráfico son muy similares a los que ya vimos anteriormente en el gráfico 1. Por un lado, observamos que las publicaciones más propensas al marcado ortográfico de voces extranjeras y, por lo tanto, más correctas desde el punto de vista normativo, son las revistas Le Monde Diplomatique y Actualidad Económica, con un porcentaje que supera el $80 \%$ en los dos casos. Mientras que las publicaciones que más incumplen la norma ortográfica son el periódico Público y la revista Geo, ambas con porcentajes de error muy elevados. Por otro, advertimos que la comisión de errores ortográficos y ortotipográficos en el marcado de los extranjerismos no es frecuente y se comete de forma aislada en tres publicaciones. 


\subsection{Lugar del texto en el que aparecen los extranjerismos crudos}

La última de las variables que queremos analizar es el tratamiento de las voces extranjeras en los titulares. Como refleja la tabla, hay un porcentaje muy bajo (4.5\%) de voces que aparecen en titulares:

\begin{tabular}{|c|c|c|}
\cline { 2 - 3 } \multicolumn{1}{c|}{} & $\mathrm{N}$ & $\%$ \\
\hline Titular, subtítulo o ladillo & 49 & 4.5 \\
\hline Cuerpo del texto & 1041 & 95.5 \\
\hline TOTAL & 1090 & 100.0 \\
\hline
\end{tabular}

Tabla 14. Lugar del texto en el que aparecen las voces extranjeras. Frecuencias absolutas

$\mathrm{Si}$ atendemos al grado de incorrección ortográfica que presentan los extranjerismos crudos dependiendo de su ubicación, observamos que el grado de incumplimiento de la norma en los titulares es mucho mayor que en el cuerpo del texto. Este dato resulta preocupante, pues los titulares, cuya función es la de captar la atención del lector, que, tras un vistazo, decide si seguir leyendo el resto del texto o no, son leídos por muchas más personas de las que luego leerán la información contenida en el resto del artículo; por lo tanto, consideramos que los aspectos formales en ellos y, en el caso que nos ocupa, la corrección ortográfica en cuanto al tratamiento de los extranjerismos crudos, deberían estar mejor cuidados:

\begin{tabular}{|c|c|c|}
\cline { 2 - 3 } \multicolumn{1}{c|}{} & \multicolumn{2}{c|}{ No sigue la norma académica } \\
\cline { 2 - 3 } \multicolumn{1}{c|}{} & $\mathrm{N}$ & $\%$ \\
\hline Titular, subtítulo o ladillo & $19 / 49$ & 38.8 \\
\hline Cuerpo del texto & $289 / 1041$ & 27.8 \\
\hline TOTAL & $308 / 1090$ & $28.3 / 100.0$ \\
\hline \multicolumn{2}{|c|}{$\mathrm{Chi}^{2}=2.800$} & Sig. 094 \\
\hline
\end{tabular}

Tabla 15. Incumplimiento de la norma ortográfica según el lugar del texto en el que aparecen las voces extranjeras

Desde el punto de vista lexicográfico, sin embargo, ocurre lo contrario. El incumplimiento de la norma lexicográfica es mayor en el cuerpo del texto que en los titulares, como vemos en la tabla 16: 


\begin{tabular}{|c|c|c|}
\cline { 2 - 3 } \multicolumn{1}{c|}{} & \multicolumn{2}{c|}{$\begin{array}{c}\text { Existe un término alternativo o } \\
\text { equivalente }\end{array}$} \\
\cline { 2 - 3 } \multicolumn{1}{c|}{$\mathrm{N}$} & $\%$ \\
\hline Titular, subtítulo o ladillo & $7 / 49$ & 14.3 \\
\hline Cuerpo del texto & $284 / 1041$ & 27.3 \\
\hline TOTAL & $291 / 1090$ & $26.7 / 100.0$ \\
\hline \multicolumn{2}{|c}{$\mathrm{Chi}^{2}=4.039$} & Sig. 044 \\
\hline
\end{tabular}

Tabla 16. Incumplimiento de la norma lexicográfica según el lugar del texto en el que aparecen las voces extranjeras

Si consideramos ahora el procedimiento seguido para el marcado de las voces foráneas en los titulares, obtenemos los siguientes resultados:

\begin{tabular}{|c|c|c|}
\cline { 2 - 3 } \multicolumn{1}{c|}{} & \multicolumn{2}{c|}{ Titular, subtítulo o ladillo } \\
\cline { 2 - 3 } \multicolumn{1}{c|}{} & $\mathrm{N}$ & $\%$ \\
\hline No marcado & 19 & 38.8 \\
\hline Cursiva & 1 & 2.0 \\
\hline Redonda con comillas & 29 & 59.2 \\
\hline Otros & 0 & 0.0 \\
\hline TOTAL & 49 & 100.0 \\
\hline \multicolumn{2}{|c|}{$\mathrm{Chi}^{2}=84.891$} & Sig. 000 \\
\hline
\end{tabular}

Tabla 17. Procedimiento para marcado de los titulares

La tabla revela que el procedimiento de marcado mediante el empleo de las comillas es el más frecuente, y dentro de estas, la variante de comillas simples, con un $46.9 \%$ del total, es la preferida. Así, podemos decir, que se sigue la norma académica, que permitía la sustitución de la cursiva por las comillas simples en los titulares de prensa. Asimismo, observamos que el uso de la cursiva es poco habitual y solo recogemos una voz marcada mediante este procedimiento. Por último, como ya comentamos, el amplio porcentaje de voces extranjeras ubicadas en titulares que no han sido resaltadas gráficamente de ninguna manera, el $38.8 \%$, resulta alarmante. 


\section{CONCLUSIONES}

Nuestro análisis ha demostrado que los medios de comunicación mantienen un alto grado de corrección, por lo que se refuta nuestra hipótesis de partida. A pesar de ello, existe un porcentaje de incumplimiento de las normas que se explica específicamente a través de las siguientes variables:

- La variable de la publicación ha puesto de manifiesto las diferencias existentes entre los distintos medios de comunicación analizados respecto al grado de cumplimiento de las normas ortográfica y lexicográfica. Con los datos obtenidos, podemos afirmar que Le Monde Diplomatique es la publicación más correcta, dado que se encuentra dentro de los porcentajes más bajos de incorrección ortográfica y lexicográfica; y que Público es la más incorrecta, ya que se sitúa en los dos casos entre los porcentajes más elevados de incumplimiento normativo.

- Una variable que merece especial atención es el procedimiento seguido para el marcado. El análisis nos ha mostrado que, dentro de los parámetros ortográficos de lo correcto, predomina el empleo de la cursiva; aunque también encontramos un amplio porcentaje de voces extranjeras resaltadas mediante el empleo de las comillas. En los titulares, sin embargo, se usan las comillas simples.

- Otro aspecto relevante es la clara hegemonía del inglés como idioma del que procede la mayoría de los extranjerismos crudos que penetran en nuestra lengua. Este hecho ha quedado demostrado no solo porque los anglicismos suponen alrededor de un $70 \%$ de las voces extranjeras registradas en nuestra base de datos, sino también porque todas las publicaciones incluyen un amplio número de voces en esta lengua. Sin embargo, el estudio ha puesto de manifiesto que los anglicismos presentan un grado considerable de incorrección ortográfica y lexicográfica.

- Otra conclusión que cabe mencionar, en cuanto al origen de los extranjerismos crudos, es el alto grado de corrección ortográfica que presentan los latinismos (que ronda el 90\%), a pesar de la gran novedad que introdujo la ORAE de 2010 en este ámbito: la equiparación de su tratamiento ortográfico al resto de extranjerismos procedentes de lenguas vivas.

- Por último, otro dato que queremos destacar es el hecho de que principalmente incorporemos sustantivos extranjeros a nuestro discurso en español, como ha mostrado la variable referida a la categoría morfológica. En cuanto al cumplimiento de la norma académica, ha quedado comprobado que, además de ser el grupo más numeroso, los sustantivos son también los que mayor porcentaje de incorrección ortográfica presentan. No obstante, y aunque también alcancen un porcentaje alto de incorrección lexicográfica, el grupo que más desatiende este criterio es el formado por los adjetivos.

En definitiva, nuestra investigación ha querido contribuir al estudio de los extranjerismos crudos no solo desde el ámbito lexicográfico, que ya ha sido abordado 
en múltiples ocasiones, sino también desde el ortográfico, que parece estar algo más olvidado, y que, sin embargo, a nuestros ojos, adquiere la misma importancia. El hecho de que dichas voces no se resalten como ajenas en un medio de comunicación escrito en español afecta negativamente tanto a la imagen del medio de comunicación en sí, como al lector de la publicación, al que no se le llama la atención sobre un elemento «extraño», que es posible que no reconozca o que no sepa interpretar.

REFERENCIAS BIBLIOGRÁFICAS

Fuentes primarias

$A B C(22 / 1 / 2012)$

Actualidad Económica (enero de 2012)

El Mundo (22/1/2012)

El País (22/1/2012)

Geo (enero de 2012)

Ideal (22/1/2012)

Le Monde Diplomatique (enero de 2012)

Muy Interesante (enero de 2012)

Público (22/1/2012)

Fuentes secundarias

ABC (2001): Libro de estilo ABC, Barcelona, Ariel.

AGENCIA EFE (2011): Libro del estilo urgente, Barcelona, Galaxia Gutenberg / Círculo de Lectores.

El Mundo (1996): Libro de estilo, Madrid, Temas de Hoy.

El PAís (2004): Libro de estilo, Madrid, Ediciones El País.

FUNDÉU BBVA, [en línea] <http://www.fundeu.es/> [fechas de consulta: de febrero de 2012 a junio de 2012].

GUERRERO RAMOS, Gloria (1995): Neologismos en el español actual, Madrid, Arco/Libros.

Gómez CAPUZ, Juan (2004): Los préstamos del español: lengua y sociedad, Madrid, Arco/Libros. 
Martínez De SousA, José (2003): Libro de estilo Vocento, Gijón, Trea.

MARTíNEZ DE SOUSA, José (2004): Ortografía y ortotipografía del español actual, Gijón, Trea.

ReAl ACADEMia EsPañola (2001): Diccionario de la lengua española. Madrid, Espasa Calpe, $22^{a}$ ed. [en línea] <http://www.rae.es> [fechas de consulta: de febrero de 2012 a junio de 2012].

ReAl ACADEMIA EsPaÑola (2005): Diccionario panhispánico de dudas, Madrid, Espasa/Real Academia Española, [en línea] <http://www.rae.es > [fechas de consulta: de febrero de 2012 a junio de 2012].

ReAl ACAdEMia EsPañola (1999): Ortografía de la lengua española, Madrid, Espasa/Real Academia Española.

REAl ACADEMIA EsPaÑola (2010): Ortografía de la lengua española, Madrid, Espasa/Real Academia Española. 